\title{
Association analysis of ILVBL gene polymorphisms with aspirin-exacerbated respiratory disease in asthma
}

\author{
Hun Soo Chang ${ }^{1 *}$, Jong Sook Park², Ho Sung Lee ${ }^{3}$, Jiwon Lyu ${ }^{3}$, Ji-Hye Son ${ }^{1}$, Inseon S. Choi ${ }^{4}$, \\ Hyoung Doo Shin ${ }^{5,6+}$ and Choon-Sik Park ${ }^{2^{*+}}$
}

\begin{abstract}
Background: We previously reported that the ILVBL gene on chromosome 19p13.1 was associated with the risk for aspirin-exacerbated respiratory disease (AERD) and the percent decline of forced expired volume in one second (FEV1) after an oral aspirin challenge test. In this study, we confirmed the association between polymorphisms and haplotypes of the ILVBL gene and the risk for AERD and its phenotype.

Methods: We recruited 141 AERD and 995 aspirin-tolerant asthmatic (ATA) subjects. All study subjects underwent an oral aspirin challenge (OAC). Nine single nucleotide polymorphisms (SNPs) with minor allele frequencies above 0.05 , which were present in the region from $2 \mathrm{~kb}$ upstream to $0.5 \mathrm{~kb}$ downstream of ILVBL in Asian populations, were selected and genotyped.

Results: In an allelic association analysis, seven of nine SNPs were significantly associated with the risk for AERD after correction for multiple comparisons. In a codominant model, the five SNPs making up block2 (rs2240299, rs7507755, rs 1468198, rs2074261, and rs 13301) showed significant associations with the risk for AERD (corrected $P=0.001-0.004$, OR $=0.59-0.64)$. Rs 1468198 was also significantly associated with the percent decline in FEV1 in OAC tests after correction for multiple comparisons in the codominant model (corrected $P=0.033$ ), but the other four SNPs in hapblock2 were not.

Conclusion: To the best of our knowledge, this is the first report of an association between SNPS on ILVBL and AERD. SNPS on ILVBL could be promising genetic markers of this condition.
\end{abstract}

Keywords: AERD, ILVBL, Single nucleotide polymorphism, Association, Asthma

\section{Background}

Aspirin (acetylsalicylic acid, ASA) hypersensitivity includes the ASA or other nonsteroidal anti-inflammatory drugs (NSAIDs)-induced respiratory disease of bronchoconstriction and nasal symptoms (AERD) and skin manifestations $[1,2]$. The airway of AERD is characterized by infiltration of inflammatory cells and epithelial

\footnotetext{
* Correspondence: hschang@sch.ac.kr; mdcspark@hanmail.net

${ }^{\dagger}$ Equal contributors

'Department of Medical Bioscience, Graduate School, Soonchunhyang University, 22, Soonchunhyang-ro, Asan, Chungcheongnam-do 336-745, Republic of Korea

${ }^{2}$ Division of Allergy and Respiratory Medicine, Department of Internal Medicine, Soonchunhyang University Bucheon Hospital, 1174, Jung-Dong, Wonmi-Ku, Bucheon, Gyeonggi-Do 420-021, Republic of Korea

Full list of author information is available at the end of the article
}

proliferation and disruption. Altered production of arachidonate metabolites by these cells account for the development of AERD [3].

Although AERD can be diagnosed with certainty by provocation tests, such as oral aspirin challenge (OAC) [4], OAC is a time-consuming procedure, and in some cases, serious complications can occur [2]. Thus, the development of noninvasive diagnostic methods such as the use of genetic marker sets is necessary to prevent the unexpected complications of aspirin use in susceptible patients. For the past two decades, many genetic association studies have demonstrated strong association of genetic variants on biologically plausible genes responsible for arachidonic acid metabolism, including LTC4S [5] ALOX5 
[6], CYSLT1R [7], CYSLT2R [8], PTGER [9-11], TBXAS1 [12], and TBXA2R [13], with the development of AERD. Other studies also identified that genes in the immune response and inflammatory pathways were associated with the adverse reaction to aspirin,, including $H L A-D P B 1$ [14], IL-4 [15], T-Box [16], FcepsilonR1 [17, 18], TLR3 [19], NLRP3 [20], ADAM33 [21], ADORA1 [22], ACE [23], CRTH2 [24], PPARG [25], KIF3A [26], SLC6A12 [27], SLC22A2 [28] and CACNG6 [29]. These findings suggest that additional genetic variation in the extra-arachidonate pathways could be related to the development of AERD.

To identify a new genetic predisposition for the risk for AERD, we previously performed a genome-wide association study (GWAS) using a low-density $100 \mathrm{~K}$ [30] and a denser $660 \mathrm{~K}$ BeadChip [31]. On the basis of the $660 \mathrm{~K}$ GWAS study, which involved 430,486 single nucleotide polymorphisms (SNPs) in 802 asthmatics, a fine-mapping study of 702 SNPs on 14 genes was performed; the results showed significant associations with AERD in 1138 subjects. In that study, a nonsynonymous SNP in exon 2 of $H L A$ DPB1, rs1042151 (Met105Val), showed the strongest association with the risk for AERD. In addition, the $660 \mathrm{~K}$ GWAS and fine-mapping studies revealed that the locus of ILVBL (IlvB (Bacterial Acetolactate Synthase)-Like) gene on chromosome 19p13.1 was associated with the risk for AERD and the percent decline of FEV1 after an OAC test.

ILVBL was first identified by Joutel et al. [32] from a human fetal brain cDNA library using a fragment isolated from a cosmid containing D19S841 at 19p13.1. They found that the 15-exon gene encodes a 632-amino-acid protein that shows similarity with several thiamine pyrophosphate-binding proteins identified in bacteria, yeast, and plants. Among them, the $I L V B L$ gene showed the highest homologies with two bacterial enzymes, the B isozyme of the large catalytic subunit of Escherichia coli acetohydroxy-acid synthase (AHAS) and the oxalyl-CoA decarboxylase of Oxalobacter formigenes. Therefore, ILVBL is likely involved in branched-chain amino acid or pyruvate metabolism. Although a direct relationship between ILVBL or branched amino acid metabolism and aspirin or arachidonic acid metabolism has not been reported to date, our previous observation of an association between ILVBL polymorphisms and AERD suggests that this gene and its SNPs could be involved in the pathophysiology of the condition. In this study, we tried to confirm the allelic association of ILVBL gene in our previous study by analyzing associations of genotypes and haplotypes with the risk for AERD and with the percent decline of FEV1 as its phenotype.

\section{Methods}

\section{Subjects}

We recruited 141 AERD and 995 ATA Korean subjects from the Asthma Genome Research Center, which includes nine university hospitals in Korea. All patients were diagnosed by physicians and met the definition of asthma set forth in the Global Initiative for Asthma (GINA) guidelines [33]. Atopy was defined using skin-prick test for 24 common inhalant allergens as described in our previous report [31]. AERD and ATA were determined using an OAC test as described previously [34, 35]. The subjects in this study were identical with those in previous study [31] except two people who were failed to genotype ILVBL locus. All subjects provided informed written consent to participate in the study. All of the subjects provided written informed consent, and the protocol was approved by the Ethics Committee of Soonchunhyang University Hospital (approval No. SCHBC-IRB-2010005).

\section{Genotyping}

Twelve ILVBL polymorphisms were selected using the Asian population database from the International HapMap Project database (http://hapmap.ncbi.nlm.nih.gov/) and the NCBI database (http://www.ncbi.nlm.nih.gov). SNP selection was based on the following scheme. First, candidate SNPs were extracted from the intragenic region including $2 \mathrm{~kb}$ of the $5^{\prime}$ region of each gene using Asian population data in the International HapMap database, and then LD structures of each gene were analyzed using SNPs with $>5 \%$ minor allele frequencies. A representative of the SNPs in almost absolute LD $\left(\left|\mathrm{D}^{\prime}\right|=1\right.$ and $\left.r^{2}>0.95\right)$ was selected. A total of 702 SNPs were selected and genotyped using the GoldenGate assay with VeraCode microbeads (Illumina, Inc.) [36]. This was followed by scanning using the BeadXpress ${ }^{\bullet}$ system (Illumina, Inc.).

\section{Statistics}

We used Lewontin's $D^{\prime}\left(\left|D^{\prime}\right|\right)$ and $r^{2}$ to measure linkage disequilibrium between biallelic loci [37]. The genotype and haplotype distributions were analyzed using logistic regression models with age (continuous value), gender $($ male $=0$, female $=1)$, and smoking status (non-smoker $=0$, ex-smoker $=1$, smoker $=2$ ) as covariates. Differences in the rates of decline in FEV1 following ASA challenge among the genotypes and haplotypes were examined using a type III generalized linear model. The data were managed and analyzed using SAS version 9.1 (SAS Inc., Cary, NC, USA), SPSS version 12.0 (SPSS Inc., Chicago, IL, USA) and PLINK version 1.9 (https://www.cog-genomics.org/ plink2) [38]. For correction of $P$-values, the effective number of independent markers in ILVBL was 
calculated using the software SNPSpD (https://neurogenetics.qimrberghofer.edu.au/SNPSpD) [39]. The statistical power for the association analysis was calculated using Power for Genetic Association (PGA) version 2.0 [40]. The data are expressed as means \pm standard errors of the mean (SE). P-values less than $5 \%$ were deemed to indicate statistical significance.

\section{Results}

\section{Characteristics of the study subjects}

In total, 1136 subjects were recruited from the asthma cohort, and their clinical characteristics are summarized in Table 1. AERD patients had a younger age of onset, higher proportion of smokers and nonsmokers, lower body mass index, and lower methacholine PC20 values than ATA patients. As expected, compared to ATA patients, the AERD subjects had a large percent decline of FEV1 after ASA challenge, a high ratio of patients with Water's view, and a high neutrophil count in sputum $(P$ $<0.05$ ). Thus, age of onset, smoking status, and BMI, which were not related to AERD, were considered covariates in further analyses of genetic associations.

\section{Frequency, heterozygosity, and the Hardy-Weinberg equilibrium of SNPs in ILVBL}

According to dbSNP (http://www.ncbi.nlm.nih.gov/SNP) and Hapmap DB (http://hapmap.ncbi.nlm.nih.gov), nine SNPs with minor allele frequencies above 0.05 are present in the region from $2 \mathrm{~kb}$ upstream to $0.5 \mathrm{~kb}$ downstream of ILVBL in Asian populations (Han
Chinese and Japanese): rs2074267, rs4141356, rs718100, rs2074265, rs2240299, rs7507755, rs1468198, rs2074261, and rs 13301. Among them, two were in the 5'-UTR (rs2074267 and rs4141356), five were in the intronic sequences (rs718100, rs2240299, rs7507755, rs 1468198 and rs2074261), one was in the coding region (rs2074265, L213 L), and one was in the 3' region downstream of the gene (rs13301). The gene map and location of the SNPs are presented in Fig. 1a.

The Hardy-Weinberg equilibrium of the nine SNPs are summarized in Additional file 1: Table S1. The distributions of all loci were in Hardy-Weinberg equilibrium in both AERD and ATA subjects $(P>0.01)$. The calculated linkage disequilibrium coefficients $\left|\mathrm{D}^{\prime}\right|$ and $r^{2}$ among the SNPs revealed that ILVBL was parsed into two LD blocks (BLs) and that there were four major haplotypes (frequency >0.01) for each of BL1 and BL2 (Fig. 1b-c). Among the four common haplotypes of BL1, haplotype1 (BL1ht2) was excluded from further statistical analysis because it was almost equivalent to $r s 718100$ and rs2074265. Similarly, only haplotype3 (BL2ht3) and haplotype4 (BL2ht4) were used for further statistical analysis because BL2ht1 was almost equivalent to rs1468198, and BL2ht2 was almost the same as rs2240299 and $r s 7507755$.

\section{Associations between ILVBL polymorphisms and the risk for and phenotypes of AERD in asthmatics}

The ILVBL polymorphisms and haplotypes were analyzed in terms of their associations with the risk for

Table 1 Clinical characteristics of study subjects

\begin{tabular}{|c|c|c|c|}
\hline & ATA & AERD & $P$ \\
\hline $\mathrm{N}$ & 995 & 141 & - \\
\hline Sex (male, \%) & $38.5 \%$ & $38.3 \%$ & 0.965 \\
\hline Age (yr) & $44.8 \pm 0.49$ & $42.39 \pm 1.26$ & 0.082 \\
\hline Age of onset (yr) & $38.82 \pm 0.53$ & $34.5 \pm 1.53$ & 0.007 \\
\hline Smoking status (NS/ES/SM, \%) & $69.6 / 16.6 / 13.7$ & $79.4 / 5.0 / 15.6$ & 0.002 \\
\hline Body mass index (kg/m2) & $24.38 \pm 0.11$ & $23.65 \pm 0.3$ & 0.023 \\
\hline FEV1 before ASA challenge (\% predicted) & $83.42 \pm 0.63$ & $80.52 \pm 1.76$ & 0.124 \\
\hline Decline of FEV1 after ASA challenge (\%) & $3.83 \pm 0.16$ & $32.42 \pm 1.08$ & $1.14 \times 10^{-53}$ \\
\hline $\log (P C 20$ methacholine $(\mathrm{mg} / \mathrm{mL}))$ & $0.36 \pm 0.02$ & $-0.02 \pm 0.07$ & $1.13 \times 10^{-7}$ \\
\hline Atopy $(Y, \%)$ & $51.9 \%$ & $48.2 \%$ & 0.419 \\
\hline Serum total lgE (kU/L) & $393.02 \pm 20.22$ & $411.2 \pm 60.71$ & 0.768 \\
\hline Urticaria $(Y, \%)$ & $22.0 \%$ & $19.9 \%$ & 0.562 \\
\hline Water's view (Y, \%) & $34.7 \%$ & $59.6 \%$ & $1.14 \times 10^{-8}$ \\
\hline Peripheral eosinophil count & $119.88 \pm 4.72$ & $112.2 \pm 13.97$ & 0.603 \\
\hline Sputum eosinophil (\%) & $33.37 \pm 1.26$ & $32.65 \pm 3.83$ & 0.858 \\
\hline Sputum neutrophil (\%) & $5.66 \pm 0.51$ & $11.35 \pm 2.31$ & 0.018 \\
\hline
\end{tabular}

ATA aspirin tolerant asthmatics, $A E R D$ aspirin-exacerbated respiratory disease, NS never smokers, ES ex-smokers, SM current smokers Numeric data were presented as mean \pm standard error

$P$ values were obtained using independent t-test or $X^{2}$ test 
A. ilvB (bacterial acetolactate synthase)-like (ILVBL) on chromosome 19p13.1

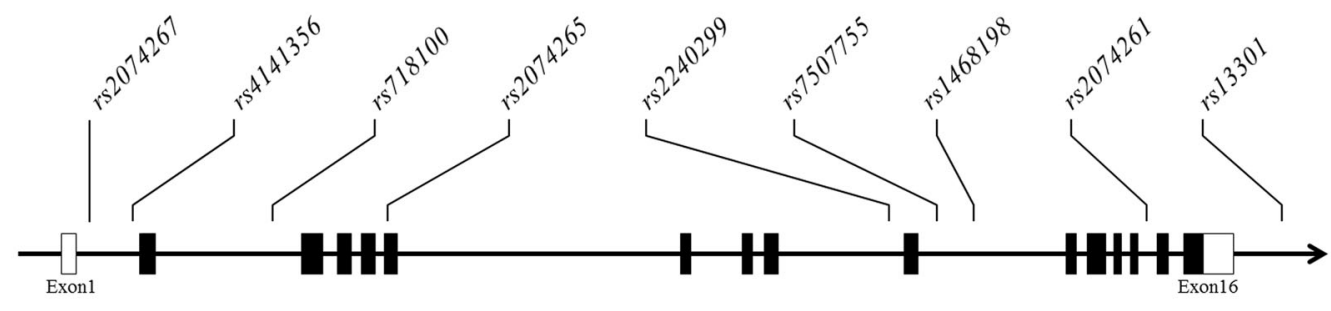

B. LDs among $I L V B L$ polymorphisms

\begin{tabular}{|c|c|c|c|c|c|c|c|c|c|c|}
\hline & \multicolumn{9}{|c|}{$r^{2}$} \\
\hline & & $\begin{array}{l}\hat{b} \\
\hat{y} \\
\hat{\sigma} \\
\hat{v} \\
\hat{2}\end{array}$ & $\frac{b}{\infty}$ & $\frac{8}{\infty}$ & 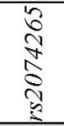 & 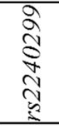 & $\begin{array}{l}n \\
\hat{2} \\
\frac{1}{2}\end{array}$ & $\begin{array}{l}\infty \\
a \\
\infty \\
\vdots \\
\vdots \\
\vdots \\
2\end{array}$ & 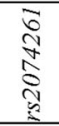 & $\begin{array}{l}\overline{0} \\
m \\
m \\
i\end{array}$ \\
\hline \multirow{9}{*}{$\left|\mathrm{D}^{\prime}\right|$} & $r s 2074267$ & - & 0.26 & 0.36 & 0.34 & 0.23 & 0.23 & 0.12 & 0.14 & 0.15 \\
\hline & $r s 4141356$ & 0.77 & - & 0.82 & 0.80 & 0.40 & 0.40 & 0.60 & 0.50 & 0.50 \\
\hline & rs718100 & 0.98 & 0.97 & - & 0.96 & 0.90 & 0.90 & 0.10 & 0.80 & 0.90 \\
\hline & $r s 2074265$ & 0.94 & 0.95 & 0.99 & - & 0.10 & 0.10 & 0.10 & 0.90 & 0.90 \\
\hline & $r s 2240299$ & 0.56 & 0.37 & 0.59 & 0.59 & - & 1.00 & 0.48 & 0.53 & 0.53 \\
\hline & rs 7507755 & 0.56 & 0.37 & 0.59 & 0.59 & 1.00 & - & 0.48 & 0.53 & 0.53 \\
\hline & $r s 1468198$ & 0.42 & 0.32 & 0.42 & 0.43 & 0.99 & 0.99 & - & 0.87 & 0.86 \\
\hline & $r s 2074261$ & 0.45 & 0.30 & 0.41 & 0.42 & 0.99 & 0.99 & 0.98 & - & 0.99 \\
\hline & rs 13301 & 0.45 & 0.30 & 0.41 & 0.42 & 0.99 & 0.99 & 0.97 & 1.00 & - \\
\hline
\end{tabular}

C. Haplotype of $I L V B L$

$1 \mathrm{~kb}$

\begin{tabular}{|c|c|c|c|c|c|c|c|c|c|c|c|c|}
\hline & \multicolumn{5}{|c|}{ Block 1} & & \multicolumn{6}{|c|}{ Block 2} \\
\hline & 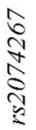 & 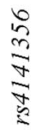 & $\frac{8}{\infty}$ & 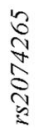 & Freq. & & 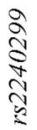 & $\begin{array}{l}n \\
\hat{n} \\
\hat{s} \\
\frac{n}{2} \\
\frac{2}{2}\end{array}$ & $\begin{array}{l}\infty \\
a \\
\infty \\
b \\
\frac{1}{2} \\
\vdots 2\end{array}$ & 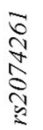 & $\begin{array}{l}\overrightarrow{0} \\
m \\
m \\
\overrightarrow{2}\end{array}$ & Freq. \\
\hline BL1ht1 & $\mathrm{C}$ & A & G & A & 0.364 & BL2ht 1 & $\mathrm{C}$ & A & $\mathrm{C}$ & A & $\mathrm{C}$ & 0.484 \\
\hline$B L 1 h t 2$ & A & $\mathrm{G}$ & $\mathrm{T}$ & $\mathrm{C}$ & 0.347 & BL2ht2 & $\mathrm{T}$ & G & $\mathrm{T}$ & $\mathrm{C}$ & $\mathrm{T}$ & 0.336 \\
\hline BLIht3 & A & A & G & $\mathrm{A}$ & 0.239 & $B L 2 h t 3$ & $\mathrm{C}$ & A & $\mathrm{T}$ & $\mathrm{C}$ & $\mathrm{T}$ & 0.145 \\
\hline BLIht4 & $\mathrm{C}$ & G & $\mathrm{G}$ & $\mathrm{A}$ & 0.036 & BL2ht4 & $\mathrm{C}$ & A & $\mathrm{T}$ & A & $\mathrm{C}$ & 0.027 \\
\hline Others & . & . & . & . & 0.013 & Others & . & . & . & . & . & 0.007 \\
\hline
\end{tabular}

Fig. 1 (a) Schematic gene map and SNPs in the ILVBL gene on chromosome 19p13.1. Black boxes represent coding exons and white boxes represent 5' and 3' UTRs. (b) Pairwise linkage disequilibrium among ILVBL SNPs. Shaded boxes represent haplotype blocks. (c) Haplotypes and their frequencies in each haplotype block

AERD using multiple logistic regression models. In the allelic association analysis, seven of nine SNPs were significantly associated with the risk for AERD after correction for multiple comparisons (Table 2). The MAFs of rs2074265 and rs718100 in block1 tended to be higher in AERD with marginal $P$ values (corrected $P=0.046-0.049$ ). In contrast, the MAFs of rs2240299, rs7507755, rs1468198, rs2074261, and rs13301, which were in block2, were significantly lower in AERD than in ATA (corrected $P=0.001-$ 0.003). In the codominant model, the five SNPs making up block2 showed significant associations with the risk for AERD (corrected $\mathrm{P}=0.001-0.004$, OR $=0.59$ 0.64; Table 3), but none in block1 were associated with AERD (corrected $P>0.05$ ). Statistical powers for the association of $r s 1468198$ were $91.0 \%, 97.8 \%$ and $77.8 \%$ for codominant, dominant, and recessive model, respectively. Although the number of minor allele homozygotes on rs2240299 and rs7507755 was small $(n=7)$, the powers for other significant associations, including rs2240299 and rs7507755, were between $82.1 \%$ and $89.8 \%$.

Because ASA-induced decline in $\mathrm{FEV}_{1}$ is the most important parameter for the diagnosis of ASA intolerance in asthmatics, we tested the associations between SNPs and haplotypes and the rate of decline in $\mathrm{FEV}_{1}$ following ASA challenge (Table 4). Among the nine SNPs, $r s 1468198$ showed a significant association with the percent decline in FEV1 in OAC tests after correction for multiple comparisons in the codominant model (corrected $P=0.033$ ). Common allele homozygotes showed a greater percent decline than did minor allele homozygotes $(8.02 \pm 0.76$ vs. $5.67 \pm 0.54)$. The other four SNPs in hapblock2 also showed significant associations with the percent reduction of FEV1; however, these were not statistically significant after correction for multiple comparisons. None of the common haplotypes showed an association with the percent reduction of FEV1 by OAC. The results of covariate-unadjusted models of the analyses using independent $t$-test and one-way ANOVA were similar; only rs 1468198 showed a significant association with the percent reduction of FEV1 in the codominant model (corrected $P=0.034$; data not shown).

\section{Association analysis using rs1468198 as a covariate}

SNPs in block2 were in high linkage disequilibrium $\left(\left|\mathrm{D}^{\prime}\right|>0.97\right.$ and $r^{2}>0.5$; Fig. 1b). To evaluate possible causative SNPs in the block independent of rs1468198, which was the most significant SNP, we tested the association between genotypes and AERD and percent decline of FEV1 using rs1468198 as a 
Table 2 Comparison of minor allele and haplotype frequencies in ILVBL gene with the risk of AERD

\begin{tabular}{|c|c|c|c|c|c|c|c|}
\hline \multirow[t]{2}{*}{ Locus } & \multirow[t]{2}{*}{ Allele } & \multirow[t]{2}{*}{ Location } & \multicolumn{2}{|l|}{ MAF } & \multirow[t]{2}{*}{ OR $[95 \% \mathrm{Cl}]$} & \multirow[t]{2}{*}{$P^{*}$} & \multirow[t]{2}{*}{$P_{\text {corr }}^{* *}$} \\
\hline & & & AERD & ATA & & & \\
\hline rs2074267 & $C>A$ & $5^{\prime}-U T R$ & 0.358 & 0.414 & $0.79[0.61-1.03]$ & 0.076 & 0.699 \\
\hline rs4141356 & $G>A$ & $5^{\prime}-U T R$ & 0.447 & 0.378 & $1.33[1.03-1.71]$ & 0.027 & 0.250 \\
\hline rs718100 & $T>G$ & intron 2 & 0.429 & 0.344 & $1.44[1.11-1.85]$ & 0.005 & 0.046 \\
\hline rs 2074265 & $C>A$ & Exon 6 (L213 L) & 0.433 & 0.348 & $1.43[1.11-1.84]$ & 0.005 & 0.049 \\
\hline$r s 2240299$ & $T>C$ & intron 9 & 0.241 & 0.352 & $0.58[0.44-0.78]$ & $2.28 \times 10^{-4}$ & 0.002 \\
\hline rs 7507755 & $G>A$ & intron 10 & 0.241 & 0.352 & $0.59[0.44-0.78]$ & $2.38 \times 10^{-4}$ & 0.002 \\
\hline rs 1468198 & $C>T$ & intron 10 & 0.475 & 0.603 & $0.60[0.46-0.77]$ & $6.11 \times 10^{-5}$ & 0.001 \\
\hline rs 2074261 & $C>A$ & intron 14 & 0.379 & 0.501 & $0.61[0.47-0.79]$ & $1.41 \times 10^{-4}$ & 0.001 \\
\hline rs13301 & $T>C$ & 3'-flanking & 0.387 & 0.502 & $0.63[0.48-0.81]$ & $2.82 \times 10^{-4}$ & 0.003 \\
\hline BLiht1 & $C A G A$ & - & 0.316 & 0.371 & $0.78[0.60-1.02]$ & 0.072 & 0.580 \\
\hline BLiht3 & $A A G A$ & - & 0.220 & 0.242 & $0.88[0.65-1.19]$ & 0.410 & 1.000 \\
\hline BLiht4 & CGGA & - & 0.032 & 0.037 & $0.86[0.43-1.75]$ & 0.684 & 1.000 \\
\hline BL2ht3 & CATCT & - & 0.135 & 0.146 & $0.91[0.63-1.31]$ & 0.608 & 1.000 \\
\hline BL2ht4 & CATAC & - & 0.021 & 0.028 & $0.75[0.32-1.76]$ & 0.508 & 1.000 \\
\hline
\end{tabular}

MAF minor allele frequency, ATA aspirin tolerant asthmatics, $A E R D$ aspirin-exacerbated respiratory disease, $O R$ odd ratio, $C l$ confidence interval

${ }^{*} P$ values were obtained using logistic regression analysis controlling age of onset, smoking status and BMI as covariates

${ }^{* *}$ Corrected P values for multiple comparison using SNPSpD

covariate, together with age of onset, smoking status, and BMI. No SNP other than rs1468198 showed an association with AERD or percent decline of FEV1 (Table 5). These results indicate that the observed associations between other SNPs in block2 and AERD were based on their tight LD with rs1468198.

\section{Discussion}

Based on the results of our previous GWAS study for AERD, we evaluated the associations between ILVBL polymorphisms and the risk for AERD and percent decline of FEV1 after OAC tests in subjects with asthma. In our previous GWAS, among three SNPs in ILVBL on the 660 W BeadChip, rs2240299, an intronic SNP in $I L V B L$, showed a significant association with the risk for AERD (odds ratio $=0.51[0.37-0.72], \quad P=7.61 \times 10^{-5}$ ) and the percent decline of FEV1 after an OAC test $(P=$ $0.004)$. In the present fine genotyping and association study for validation, among nine SNPs in the ILVBL gene, rs1468198 and SNPs linked with rs1468198 showed significant associations with the phenotypes of AERD. Although regarding multiple comparison derived by three genetic model and two outcome testing, the association between $r s 1468198$ and the risk of AERD were statistically significant $(\mathrm{SNPSpD}$ corrected $\mathrm{P} \times 3$ genetic models $\times 2$ phentoypes $=0.006)$. Our observations suggest that the $I L V B L$ gene and its locus play a role in the pathogenesis of AERD. To the best of our knowledge, there is no previous report of a genetic association with AERD, or any other disease.
Aspirin has antipyretic, anti-inflammatory, analgesic, and antiplatelet effects by irreversible inhibition of cyclooxygenase-1 (COX-1) and regulation of various receptors and signaling molecules. The analgesic effects of non-steroidal anti-inflammatory drugs (NSAID) are mediated by beta 2 adrenergic receptors ( $\beta 2 A D R)$. Suleyman et al. [41] and Caidrci et al. [42] independently revealed that the analgesic and anti-inflammatory effects of NSAIDs including aspirin were lost in adrenalectomized rats compared to normal rats. The analgesic and antiinflammatory effects of NSAIDs were restored by pretreatment of rats with prednisolone and adrenalin, an effect which was inhibited by beta 2 receptor antagonists but not by alpha1, alpha2, or beta1 antagonists [41, 42]. Moreover, polymorphisms in the $\beta 2 \mathrm{ADR}$ were associated with AERD and with aspirin-intolerant acute urticaria $[43,44]$. In addition, aspirin and its derivatives prevent cancer cell proliferation by reducing epidermal growth factor receptor (EGFR) expression and downstream signal transduction [45-47]. The therapeutic/chemopreventative effects of aspirin in cancer are also mediated by direct inhibition of integrin-linked kinase (ILK) signaling and by decreased expression of c-Myc in cancer cells [48-51].

Due to its high structural similarity with bacterial acetolactate synthases, ILVBL has been postulated to be involved in pyruvate or branched amino acid metabolism, but the precise function of the gene product is unclear. However, recent proteomic studies have revealed that the ILVBL protein interacts with various factors, including $\beta 2 \mathrm{ADR}, \mathrm{EGFR}$, ILK, and c-MYC 


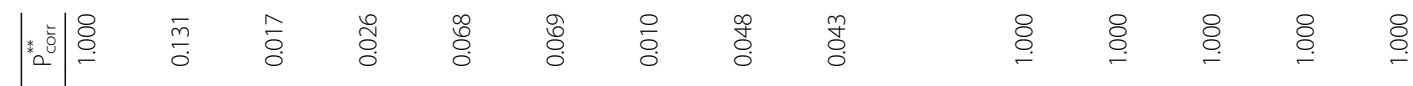

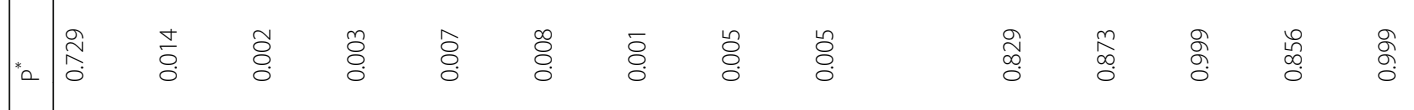

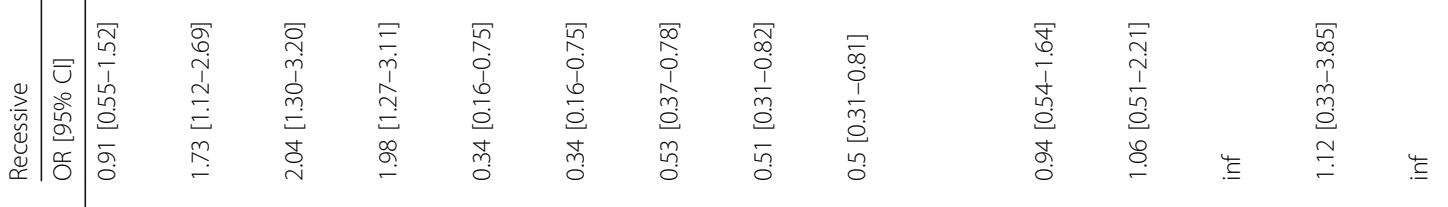

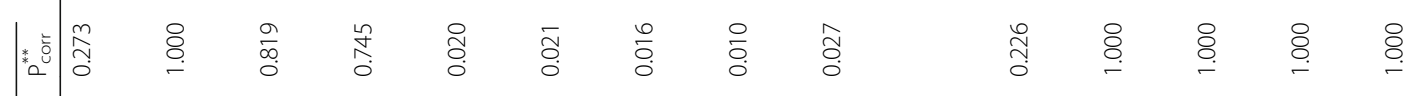
.

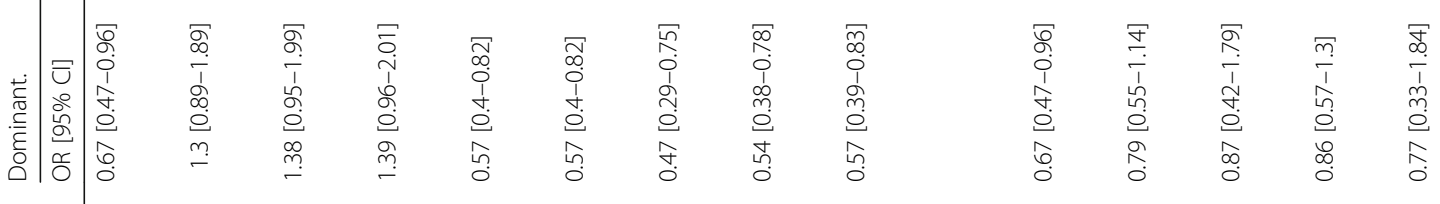

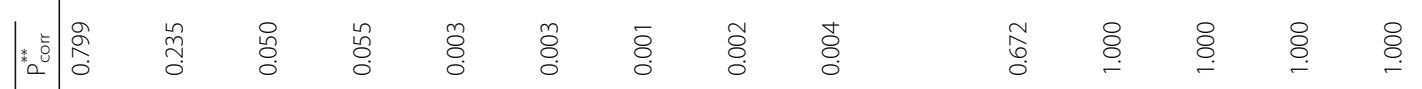
.

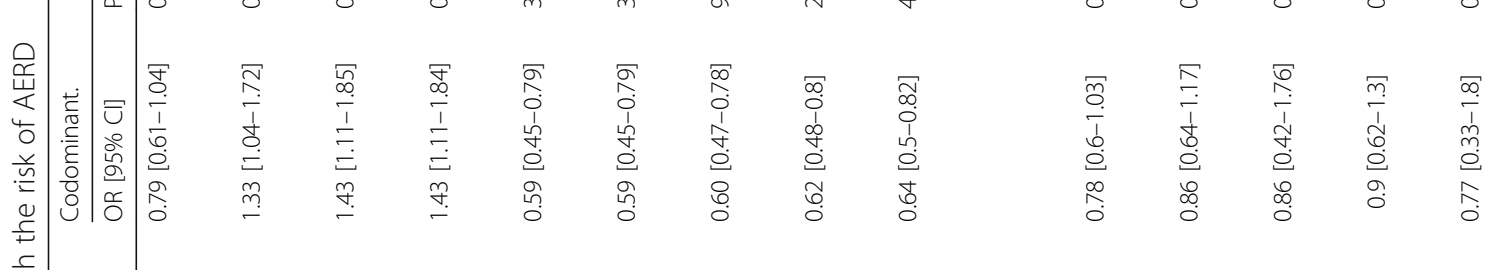

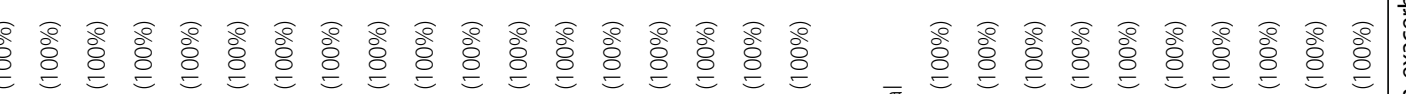

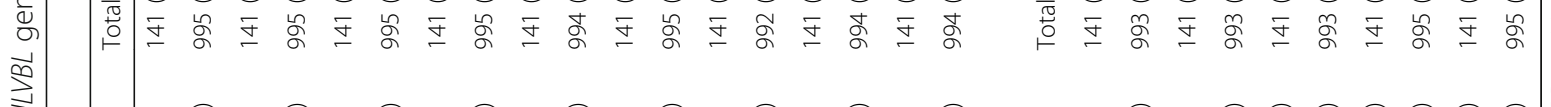

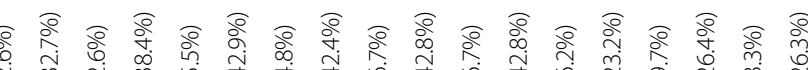

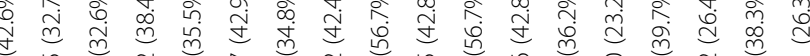

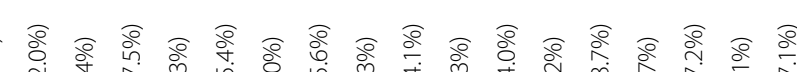

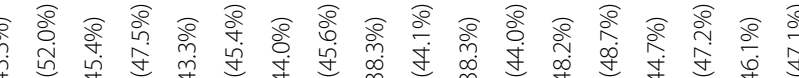

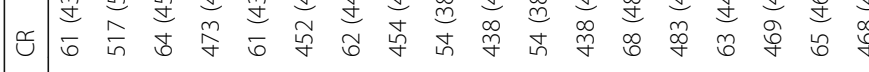

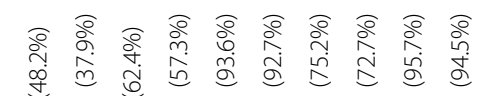
菖言

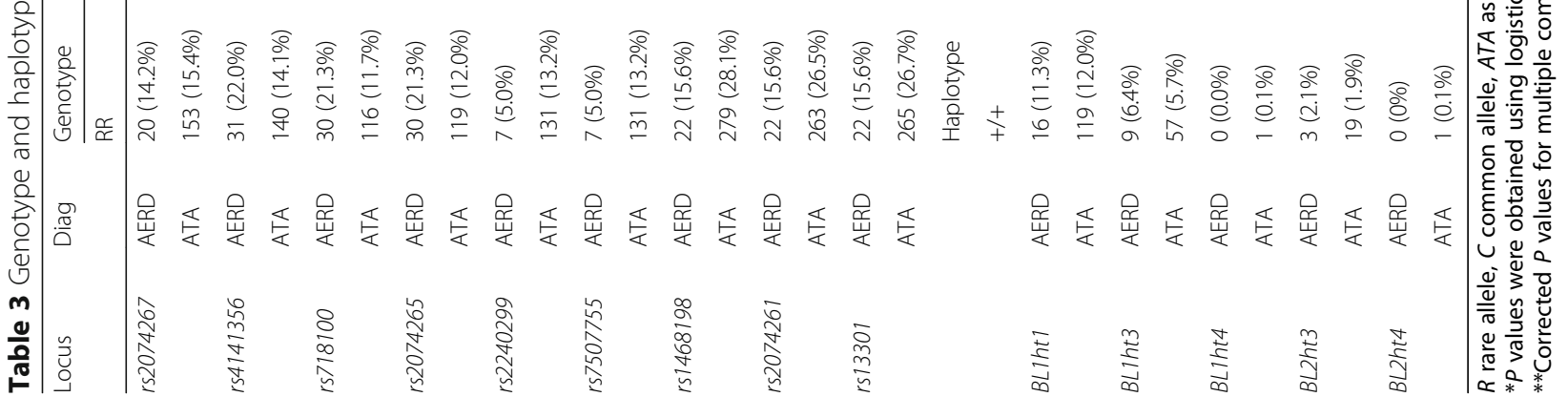


Table 4 Genotype and haplotype association analysis in ILVBL gene with \% decline of FEV1 after oral aspirin challenge test in asthmatics

\begin{tabular}{|c|c|c|c|c|c|c|c|c|c|}
\hline \multirow[t]{2}{*}{ Locus } & \multicolumn{3}{|l|}{ Genotype } & \multicolumn{2}{|c|}{ Codominant } & \multicolumn{2}{|c|}{ Dominant } & \multicolumn{2}{|c|}{ Recessive } \\
\hline & $\mathrm{RR}$ & $C R$ & CC & $\overline{P^{*}}$ & $P_{\text {corr }}^{* *}$ & $\overline{P^{*}}$ & $P_{\text {corr }}^{* *}$ & $\overline{P^{*}}$ & $P_{\text {corr }}^{* *}$ \\
\hline rs 2074267 & $6.95 \pm 0.76(173)$ & $6.29 \pm 0.46(578)$ & $7.18 \pm 0.59(385)$ & 0.413 & 1.000 & 0.207 & 1.000 & 0.907 & 1.000 \\
\hline rs4141356 & $7.53 \pm 0.90(171)$ & $6.57 \pm 0.48(537)$ & $6.51 \pm 0.51$ & 0.271 & 1.000 & 0.484 & 1.000 & 0.238 & 1.000 \\
\hline rs718100 & $8.27 \pm 1.04(146)$ & $6.36 \pm 0.49(513)$ & $6.56 \pm 0.48(477)$ & 0.138 & 1.000 & 0.500 & 1.000 & 0.043 & 0.391 \\
\hline rs 2074265 & $8.15 \pm 1.02(149)$ & $6.46 \pm 0.49(516)$ & $6.48 \pm 0.48(471)$ & 0.120 & 1.000 & 0.389 & 1.000 & 0.058 & 0.535 \\
\hline rs2240299 & $4.99 \pm 0.61(138)$ & $6.33 \pm 0.49(492)$ & $7.51 \pm 0.53(505)$ & 0.006 & 0.053 & 0.015 & 0.139 & 0.041 & 0.376 \\
\hline rs7507755 & $4.99 \pm 0.61$ (138) & $6.33 \pm 0.49(492)$ & $7.50 \pm 0.53(506)$ & 0.006 & 0.055 & 0.016 & 0.145 & 0.041 & 0.379 \\
\hline rs 1468198 & $5.67 \pm 0.54(301)$ & $6.59 \pm 0.47(551)$ & $8.02 \pm 0.76(281)$ & 0.004 & 0.033 & 0.008 & 0.072 & 0.033 & 0.307 \\
\hline rs2074261 & $5.76 \pm 0.57(285)$ & $6.47 \pm 0.46(532)$ & $7.88 \pm 0.71$ (318) & 0.006 & 0.057 & 0.009 & 0.078 & 0.061 & 0.560 \\
\hline \multirow[t]{3}{*}{ rs13301 } & $5.78 \pm 0.57(287)$ & $6.62 \pm 0.47(533)$ & $7.63 \pm 0.69$ (315) & 0.015 & 0.139 & 0.032 & 0.291 & 0.064 & 0.590 \\
\hline & \multicolumn{9}{|l|}{ Haplotype } \\
\hline & $+/+$ & $-/+$ & $-1-$ & & & & & & \\
\hline BLIht1 & $7.25 \pm 0.55$ & $6.22 \pm 0.46(555)$ & $6.78 \pm 0.82(135)$ & 0.276 & 1.000 & 0.151 & 1.000 & 0.949 & 1.000 \\
\hline BLiht3 & $6.89 \pm 0.44(657)$ & $6.22 \pm 0.52(411)$ & $7.58 \pm 1.51(66)$ & 0.693 & 1.000 & 0.563 & 1.000 & 0.845 & 1.000 \\
\hline BLiht4 & $6.66 \pm 0.34(1053)$ & $7.16 \pm 1.24(80)$ & $3.00(1)$ & 0.964 & 1.000 & 0.943 & 1.000 & 0.827 & 1.000 \\
\hline BL2ht3 & $6.70 \pm 0.38(829)$ & $6.65 \pm 0.67(285)$ & $6.91 \pm 1.77(22)$ & 0.818 & 1.000 & 0.752 & 1.000 & 0.845 & 1.000 \\
\hline BL2ht4 & $6.72 \pm 0.34(1075)$ & $6.21 \pm 1.39(60)$ & $0.00(1)$ & 0.564 & 1.000 & 0.612 & 1.000 & 0.524 & 1.000 \\
\hline
\end{tabular}

$R$ rare allele, $C$ common allele

* $P$ values were obtained using linear regression analysis controlling age of onset, smoking status and BMI as covariates

${ }^{* *}$ Corrected $P$ values for multiple comparison using SNPSpD

[52-55]. Therefore, the ILVBL gene could be involved in the functions and regulation of these proteins, which are related to the mechanism of action of aspirin. Thus, the roles and functions of ILVBL and its interacting proteins in the pathophysiology of aspirin hypersensitivity warrant further studies.

In this study, rs 1468198 located on the 10th intron of ILVBL and SNPs on the same hapblock with rs1468198 showed significant associations with AERD phenotype. After adjusting for $r s 1468198$, the remaining SNPs showed no significant association, which suggests that rs1468198 is the most promising causative polymorphism for AERD. With the exception of a report of an association between copy number variation in the region including $I L V B L$ and the pathogenesis of seizure, intrauterine growth retardation, learning disability, microcephaly, and intellectual disability [56], there has been no report of associations between SNPs in ILVBL and disease. According to functional estimation of the SNPs linked with rs 1468198 in Asian populations (SNPinfo Web Server, https://snpinfo.niehs.nih.gov/), rs1468198 did not show transcription factor binding, splicing site, splicing regulation, or miRNA molecular functions. Instead, rs2074262, which was not included in this study but which is located 1208 bp downstream of rs1468198 and 359 bp upstream of rs 2074261, is located on a splicing enhancer and is highly conserved. This in silico prediction suggests that the observed association between $r s 1468198$ and AERD could be due to its high LD with $r s 2074262$, which could affect post-transcriptional processing of ILVBL. In addition, although it was not statistically significant after correction of multiple comparison, $r s 2074262$ showed a trend of association with mRNA expression of RAR related orphan receptor A (RORA, $P=0.00007$ ) and somatostatin receptor 3 (SSTR3, $P=0.0001$ ) gene in expression quatitative trait loci (eQTL) analysis using ENCODE dataset (https:// www.encodeproject.org). These genes may be involved in asthma- and AERD-related cytokine signaling such as IL4 and IL-13 (http://reactome.org). Thus, the roles of ILVBL, as well as the functional consequences of rs1468198 and rs2074262, in the pathophysiology of AERD should be evaluated in further study.

The present study has several limitations. Firstly, only nine SNPs in the ILVBL gene were evaluated in this study. In the ILVBL gene, which is spanning $11 \mathrm{~kb}$ of chromosome 19p13.1, 1548 SNPs registered in dbSNP (http://www.ncbi.nlm.nih.gov/snp), including 29 SNPs with MAF $>0.05$. Although the SNPs analyzed in this study tagged haplotypes on each hapblock (Fig. 1c), the other SNPs may be directly associated with AERD itself or related phenotypes. This possibility should be confirmed in further replication studies that include high-density markers with low frequencies and use nextgeneration sequencing or exome variant analyses. In 
Table 5 The association of SNPs in ILVBL gene with the risk of AERD and \% decline of FEV1 after adjusting rs 1468198

\begin{tabular}{|c|c|c|c|}
\hline \multicolumn{4}{|c|}{ The risk of AERD } \\
\hline SNP & OR $[95 \% \mathrm{Cl}]$ & $P^{*}$ & $\mathrm{P}_{\text {corr }}^{\dagger}$ \\
\hline rs 13301 & $1.16[0.55-2.41]$ & 0.699 & 1.000 \\
\hline rs2074261 & 0.99 [0.47-2.09] & 0.975 & 1.000 \\
\hline rs7507755 & 0.78 [0.52-1.17] & 0.226 & 1.000 \\
\hline rs2240299 & $0.78[0.52-1.16]$ & 0.220 & 1.000 \\
\hline rs2074265 & $1.24[0.94-1.61]$ & 0.123 & 1.000 \\
\hline rs718100 & $1.24[0.95-1.63]$ & 0.109 & 1.000 \\
\hline rs4141356 & 1.18 [0.91-1.53] & 0.222 & 1.000 \\
\hline rs2074267 & $0.96[0.72-1.28]$ & 0.772 & 1.000 \\
\hline \multicolumn{4}{|c|}{ \% decline of FEV1 } \\
\hline SNP & $\beta( \pm \mathrm{SE})$ & $P^{* *}$ & $P_{\text {corr }}^{\dagger}$ \\
\hline rs13301 & $1.08 \pm 1.25$ & 0.387 & 1.000 \\
\hline rs2074261 & $0.06 \pm 1.29$ & 0.964 & 1.000 \\
\hline rs7507755 & $-0.64 \pm 0.69$ & 0.353 & 1.000 \\
\hline rs2240299 & $-0.65 \pm 0.69$ & 0.344 & 1.000 \\
\hline rs2074265 & $0.34 \pm 0.51$ & 0.505 & 1.000 \\
\hline rs718100 & $0.31 \pm 0.51$ & 0.535 & 1.000 \\
\hline rs4141356 & $0.19 \pm 0.49$ & 0.702 & 1.000 \\
\hline rs2074267 & $0.12 \pm 0.52$ & 0.814 & 1.000 \\
\hline
\end{tabular}

*,** P values were obtained using logistic and linear regression analysis, respectively, controlling age of onset, smoking status, BMI, and genotype of rs1468198as covariates

† Corrected $\mathrm{P}$ values for multiple comparison using SNPSpD

$O R$ odd ratio, $\mathrm{Cl}$ confidence interval, $S E$ standard error

addition, population stratification bias can be introduced in genetic association studies [57]. However, we consider such a bias to be unlikely because the Korean population is reported to show a relatively high degree of genetic homogeneity [58].

\section{Conclusions}

We found a significant association between polymorphisms of $I L V B L$, a candidate gene in patients with AERD, and the risk for and phenotypes of AERD in patients with asthma. Further investigations of the biological roles of the ILVBL protein in the mechanism of action of aspirin and in the pathogenesis of AERD should be performed, particularly regarding its interactions with other proteins. To the best of our knowledge, this is the first report of an association between SNPs on $I L V B L$ and AERD. Our results also suggest that SNPs on $I L V B L$ are potential genetic markers for AERD.

\section{Additional file}

Additional file 1: Table S1. Hardy-Weinberg Equilibrium of SNPS and haplotypes in ILVBL gene. (XLS 27 kb)

\section{Abbreviations}

AERD: Aspirin-exacerbated respiratory disease; AHAS: Acetohydroxy-acid synthase; ASA: Acetylsalicylic acid, aspirin; ATA: Aspirin-tolerant asthma; BL: LD block; BMI: Body mass index; eQTL: Expression quatitative trait loci; FEV1: Forced expired volume in one second; GINA: Global Initiative for Asthma; GWAS: Genome-wide association study; Ht: Haplotype; LD: Linkage Disequilibrium; NSAID: Nonsteroidal anti-inflammatory drug; OAC: Oral aspirin challenge; PC20: Provocative concentration of methacholine causing a 20\% fall in FEV1; PGA: Power for Genetic Association; SE: Standard errors of the mean; SNP: Single nucleotide polymorphism; UTR: Untranslated region

\section{Acknowledgements}

The Biobank of Soonchunhyang University Bucheon Hospital, a member of the Korea Biobank Network, provided the specimens and data.

\section{Funding}

The Ministry of Health, Welfare, and Family Affairs, Republic of Korea, supported this study, and Soonchunhyang University provided a research grant to CS Park (HI13C0319). The funding bodies had no role.

\section{Availability of data and materials}

The data that support the findings of this study are available on request from the corresponding author (Park CS).

\section{Authors' contributions}

HSC analyzed the association between genotypes and phenotypes, and wrote the manuscript. JSP, HSL, JL and ISC participated in the subject recruitment and collected clinical information and DNA samples. JHS carried out DNA sample handling (extractions and genotyping experiments) and supported the association analysis. HDS was involved in analysis and interpretation of results. CSP designed the research study and was involved in interpretation of results, manuscript draft revisions and research supervision. All authors have read and approved the final version of this manuscript.

\section{Ethics approval and consent to participate}

All subjects provided informed written consent to participate in the study. The protocol was approved by the Ethics Committee of Soonchunhyang University Hospital (approval No. SCHBC-IRB-2010-005).

\section{Consent for publication}

Not applicable.

\section{Competing interests}

The authors declare that they have no competing interests.

\section{Publisher's Note}

Springer Nature remains neutral with regard to jurisdictional claims in published maps and institutional affiliations.

\section{Author details}

${ }^{1}$ Department of Medical Bioscience, Graduate School, Soonchunhyang University, 22, Soonchunhyang-ro, Asan, Chungcheongnam-do 336-745, Republic of Korea. ${ }^{2}$ Division of Allergy and Respiratory Medicine, Department of Internal Medicine, Soonchunhyang University Bucheon Hospital, 1174, Jung-Dong, Wonmi-Ku, Bucheon, Gyeonggi-Do 420-021, Republic of Korea. ${ }^{3}$ Division of Respiratory Medicine, Soonchunhyang University Chunan Hospital, Chunan-Si, Chungcheongnam-do 336-745, Republic of Korea. ${ }^{4}$ Department of Allergy, Chonnam National University Medical School and Research Institute of Medical Sciences, Gwangju 61469, Republic of Korea. ${ }^{5}$ Department of Life Science, Sogang University, 1 Shinsu-dong, Mapo-gu, Seoul 121-742, Republic of Korea. 'Department of Genetic Epidemiology, SNP Genetics, Inc., 1407 14th Floor, Woolim-rall'ey B, Gasan-dong,

Geumcheon-Gu, Seoul 153-803, Republic of Korea.

Received: 21 December 2016 Accepted: 7 December 2017

Published online: 16 December 2017

\section{References}

1. Samter M, Beers RF Jr. Concerning the nature of intolerance to aspirin. J Allergy. 1967;40(5):281-93. 
2. Lee RU, Stevenson DD. Aspirin-exacerbated respiratory disease: evaluation and management. Allergy Asthma Immunol Res. 2011;3(1):3-10.

3. Szczeklik A, Nizankowska E, Duplaga M. Natural history of aspirin-induced asthma. AlANE investigators. European network on aspirin-induced asthma. Eur Respir J. 2000;16(3):432-6.

4. Kowalski ML, Makowska JS. Seven steps to the diagnosis of NSAIDs hypersensitivity: how to apply a new classification in real practice? Allergy Asthma Immunol Res. 2015;7(4):312-20.

5. Sanak M, Pierzchalska M, Bazan-Socha S, Szczeklik A. Enhanced expression of the leukotriene C(4) synthase due to overactive transcription of an allelic variant associated with aspirin-intolerant asthma. Am J Respir Cell Mol Biol. 2000;23(3):290-6.

6. Choi JH, Park HS, HB O, Lee JH, Suh YJ, Park CS, et al. Leukotriene-related gene polymorphisms in ASA-intolerant asthma: an association with a haplotype of 5-lipoxygenase. Hum Genet. 2004;114(4):337-44.

7. Kim SH, Oh JM, Kim YS, Palmer L, Suh CH, Nahm DH, et al. Cysteinyl leukotriene receptor 1 promoter polymorphism is associated with aspirinintolerant asthma in males. Clinical and experimental allergy : journal of the British Society for Allergy and Clinical Immunology. 2006;36(4):433-9.

8. Park JS, Chang HS, Park CS, Lee JH, Lee YM, Choi JH, et al. Association analysis of cysteinyl-leukotriene receptor 2 (CYSLTR2) polymorphisms with aspirin intolerance in asthmatics. Pharmacogenet Genomics. 2005;15(7):483-92.

9. Jinnai N, Sakagami T, Sekigawa T, Kakihara M, Nakajima T, Yoshida K, et al. Polymorphisms in the prostaglandin E2 receptor subtype 2 gene confer susceptibility to aspirin-intolerant asthma: a candidate gene approach. Hum Mol Genet. 2004;13(24):3203-17.

10. Kim SH, Kim YK, Park HW, Jee YK, Bahn JW, Chang YS, et al. Association between polymorphisms in prostanoid receptor genes and aspirinintolerant asthma. Pharmacogenet Genomics. 2007;17(4):295-304.

11. Park BL, Park SM, Park JS, ST U, Choi JS, Kim YH, et al. Association of PTGER gene family polymorphisms with aspirin intolerant asthma in Korean asthmatics. BMB Rep. 2010;43(6):445-9.

12. SH O, Kim YH, Park SM, Cho SH, Park JS, Jang AS, et al. Association analysis of thromboxane a synthase 1 gene polymorphisms with aspirin intolerance in asthmatic patients. Pharmacogenomics. 2011;12(3):351-63.

13. Kim SH, Choi JH, Park HS, Holloway JW, Lee SK, Park CS, et al. Association of thromboxane A2 receptor gene polymorphism with the phenotype of acetyl salicylic acid-intolerant asthma. Clinical and experimental allergy : journal of the British Society for Allergy and Clinical Immunology. 2005; 35(5):585-90.

14. Dekker JW, Nizankowska E, Schmitz-Schumann M, Pile K, Bochenek G, Dyczek A, et al. Aspirin-induced asthma and HLA-DRB1 and HLA-DPB1 genotypes. Clinical and experimental allergy : journal of the British Society for Allergy and Clinical Immunology. 1997;27(5):574-7.

15. Kim BS, Park SM, Uhm TG, Kang JH, Park JS, Jang AS, et al. Effect of single nucleotide polymorphisms within the interleukin-4 promoter on aspirin intolerance in asthmatics and interleukin-4 promoter activity. Pharmacogenet Genomics. 2010;20(12):748-58.

16. Akahoshi M, Obara K, Hirota T, Matsuda A, Hasegawa K, Takahashi N, et al. Functional promoter polymorphism in the TBX21 gene associated with aspirin-induced asthma. Hum Genet. 2005;117(1):16-26.

17. Kim SH, Bae JS, Holloway JW, Lee JT, Suh CH, Nahm DH, et al. A polymorphism of MS4A2 (-109T > C) encoding the beta-chain of the highaffinity immunoglobulin E receptor (FcepsilonR1beta) is associated with a susceptibility to aspirin-intolerant asthma. Clinical and experimental allergy : journal of the British Society for Allergy and Clinical Immunology. 2006; 36(7):877-83.

18. Palikhe NS, Kim SH, Cho BY, Ye YM, Hur GY, Park HS. Association of three sets of high-affinity lgE receptor (FcepsilonR1) polymorphisms with aspirinintolerant asthma. Respir Med. 2008;102(8):1132-9.

19. Palikhe NS, Kim SH, Kim JH, Losol P, Ye YM, Park HS. Role of toll-like receptor 3 variants in aspirin-exacerbated respiratory disease. Allergy Asthma Immunol Res. 2011;3(2):123-7.

20. Hitomi Y, Ebisawa M, Tomikawa M, Imai T, Komata T, Hirota T, et al. Associations of functional NLRP3 polymorphisms with susceptibility to foodinduced anaphylaxis and aspirin-induced asthma. J Allergy Clin Immunol. 2009;124(4):779-85.e6.

21. Sakagami T, Jinnai N, Nakajima T, Sekigawa T, Hasegawa T, Suzuki E, et al. ADAM33 polymorphisms are associated with aspirin-intolerant asthma in the Japanese population. J Hum Genet. 2007;52(1):66-72.
22. Kim SH, Kim YK, Park HW, Kim SH, Kim SH, Ye YM, et al. Adenosine deaminase and adenosine receptor polymorphisms in aspirin-intolerant asthma. Respir Med. 2009;103(3):356-63.

23. Kim TH, Chang HS, Park SM, Nam BY, Park JS, Rhim T, et al. Association of angiotensin I-converting enzyme gene polymorphisms with aspirin intolerance in asthmatics. Clinical and experimental allergy : journal of the British Society for Allergy and Clinical Immunology. 2008;38(11):1727-37.

24. Palikhe NS, Kim SH, Cho BY, Ye YM, Choi GS, Park HS. Genetic variability in CRTH2 polymorphism increases eotaxin-2 levels in patients with aspirin exacerbated respiratory disease. Allergy. 2010;65(3):338-46.

25. SH O, Park SM, Park JS, Jang AS, Lee YM, ST U, et al. Association analysis of peroxisome proliferator-activated receptors gamma gene polymorphisms with asprin hypersensitivity in asthmatics. Allergy Asthma Immunol Res. 2009; (1):30-5.

26. Kim JH, Cha JY, Cheong HS, Park JS, Jang AS, ST U, et al. KIF3A, a cilia structural gene on chromosome $5 \mathrm{q} 31$, and its polymorphisms show an association with aspirin hypersensitivity in asthma. J Clin Immunol. 2011;31(1):112-21.

27. Pasaje CF, Kim JH, Park BL, Cheong HS, Chun JY, Park TJ, et al. Association of SLC6A12 variants with aspirin-intolerant asthma in a Korean population. Ann Hum Genet. 2010;74(4):326-34.

28. Park TJ, Kim JH, Bae JS, Park BL, Cheong HS, Chun JY, et al. Possible association of SLC22A2 polymorphisms with aspirin-intolerant asthma. Int Arch Allergy Immunol. 2011;155(4):395-402.

29. Lee JS, Kim JH, Bae JS, Kim JY, Park TJ, Pasaje CF, et al. Association of CACNG6 polymorphisms with aspirin-intolerance asthmatics in a Korean population. BMC Med Genet. 2010;11:138.

30. Kim JH, Park BL, Cheong HS, Bae JS, Park JS, Jang AS, et al. Genome-wide and follow-up studies identify CEP68 gene variants associated with risk of aspirin-intolerant asthma. PLoS One. 2010;5(11):e13818.

31. Park BL, Kim TH, Kim JH, Bae JS, Pasaje CF, Cheong HS, et al. Genome-wide association study of aspirin-exacerbated respiratory disease in a Korean population. Hum Genet. 2013;132(3):313-21.

32. Joutel A, Ducros A, Alamowitch S, Cruaud C, Domenga V, Marechal E, et al. A human homolog of bacterial acetolactate synthase genes maps within the CADASIL critical region. Genomics. 1996;38(2):192-8.

33. Bateman ED, Hurd SS, Barnes PJ, Bousquet J, Drazen JM, FitzGerald M, et al. Global strategy for asthma management and prevention: GINA executive summary. Eur Respir J. 2008;31(1):143-78.

34. Kim TH, Lee JY, Park JS, Park SW, Jang AS, Byun JY, et al. Fatty acid binding protein 1 is related with development of aspirin-exacerbated respiratory disease. PLoS One. 2011:6(8):e22711.

35. Nizankowska-Mogilnicka E, Bochenek G, Mastalerz L, Swierczynska M, Picado C, Scadding G, et al. EAACI/GA2LEN guideline: aspirin provocation tests for diagnosis of aspirin hypersensitivity. Allergy. 2007;62(10):1111-8.

36. Lin CH, Yeakley JM, McDaniel TK, Shen R. Medium- to high-throughput SNP genotyping using VeraCode microbeads. Methods in molecular biology (Clifton, NJ). 2009:496:129-42.

37. Barrett JC, Fry B, Maller J, Daly MJ. Haploview: analysis and visualization of LD and haplotype maps. Bioinformatics. 2005;21(2):263-5.

38. Purcell S, Neale B, Todd-Brown K, Thomas L, Ferreira MA, Bender D, et al. PLINK: a tool set for whole-genome association and population-based linkage analyses. Am J Hum Genet. 2007;81(3):559-75.

39. Nyholt DRA. Simple correction for multiple testing for single-nucleotide polymorphisms in linkage disequilibrium with each other. Am J Hum Genet. 2004;74(4):765-9.

40. Menashe I, Rosenberg PS, Chen BEPGA. Power calculator for case-control genetic association analyses. BMC Genet. 2008;9:36.

41. Suleyman $\mathrm{H}$, Halici Z, Cadirci E, Hacimuftuoglu A, Bilen $\mathrm{H}$. Indirect role of beta2-adrenergic receptors in the mechanism of anti-inflammatory action of NSAIDS. Journal of physiology and pharmacology : an official journal of the Polish Physiological Society. 2008;59(4):661-72.

42. Cadirci E, Suleyman H, Hacimuftuoglu A, Halici Z, Akcay F. Indirect role of beta2-adrenergic receptors in the mechanism of analgesic action of nonsteroidal antiinflammatory drugs. Crit Care Med. 2010;38(9):1860-7.

43. Kim HA, Ye YM, Kim SH, Hur GY, Park HS. Association of beta 2-adrenergic receptor polymorphism with the phenotype of aspirin-intolerant acute urticaria. Yonsei Med J. 2007:48(6):1079-81.

44. Kohyama K, Abe S, Kodaira K, Yukawa T, Hozawa S, Morioka J, et al. Arg16Gly beta2-adrenergic receptor gene polymorphism in Japanese patients with aspirin-exacerbated respiratory disease. Int Arch Allergy Immunol. 2011;156(4):405-11. 
45. Huang L, Wong CC, Mackenzie GG, Sun Y, Cheng KW, Vrankova K, et al. Phospho-aspirin (MDC-22) inhibits breast cancer in preclinical animal models: an effect mediated by EGFR inhibition, p53 acetylation and oxidative stress. BMC Cancer. 2014;14:141.

46. Li H, Zhu F, Boardman LA, Wang L, Oi N, Liu K, et al. Aspirin prevents colorectal cancer by normalizing EGFR expression. EBioMedicine. 2015; 2(5):447-55

47. Selvendiran K, Bratasz A, Tong L, Ignarro L, Kuppusamy P. NCX-4016, a nitro-derivative of aspirin, inhibits EGFR and STAT3 signaling and modulates $\mathrm{BCl}-2$ proteins in cisplatin-resistant human ovarian cancer cells and xenografts. Cell cycle (Georgetown, Tex). 2008;7(1):81-8.

48. Marotta A, Tan C, Gray V, Malik S, Gallinger S, Sanghera J, et al. Dysregulation of integrin-linked kinase (ILK) signaling in colonic polyposis. Oncogene. 2001;20(43):6250-7.

49. Ai G, Dachineni R, Muley P, Tummala H, Bhat GJ. Aspirin and salicylic acid decrease c-Myc expression in cancer cells: a potential role in chemoprevention. Tumour biology : the journal of the International Society for Oncodevelopmental Biology and Medicine. 2015;

50. Gottfried E, Lang SA, Renner K, Bosserhoff A, Gronwald W, Rehli M, et al. New aspects of an old drug-diclofenac targets MYC and glucose metabolism in tumor cells. PLoS One. 2013;8(7):e66987.

51. Lan F, Yue X, Han L, Yuan X, Shi Z, Huang K, et al. Antitumor effect of aspirin in glioblastoma cells by modulation of beta-catenin/T-cell factormediated transcriptional activity. J Neurosurg. 2011;115(4):780-8.

52. Roy SJ, Glazkova I, Frechette L, lorio-Morin C, Binda C, Petrin D, et al. Novel, gel-free proteomics approach identifies RNF5 and JAMP as modulators of GPCR stability. Molecular endocrinology (Baltimore, Md). 2013;27(8):1245-66.

53. Tong J, Taylor P, Moran MF. Proteomic analysis of the epidermal growth factor receptor (EGFR) interactome and post-translational modifications associated with receptor endocytosis in response to EGF and stress. Molecular \& cellular proteomics : MCP. 2014;13(7):1644-58.

54. Varjosalo M, Sacco R, Stukalov A, van Drogen A, Planyavsky M, Hauri S, et al. Interlaboratory reproducibility of large-scale human protein-complex analysis by standardized AP-MS. Nat Methods. 2013;10(4):307-14.

55. Koch HB, Zhang R, Verdoodt B, Bailey A, Zhang CD, Yates JR 3rd, et al. Large-scale identification of c-MYC-associated proteins using a combined TAP/MudPIT approach. Cell cycle (Georgetown, Tex). 2007;6(2):205-17.

56. Kaminsky EB, Kaul V, Paschall J, Church DM, Bunke B, Kunig D, et al. An evidence-based approach to establish the functional and clinical significance of copy number variants in intellectual and developmental disabilities. Genetics in medicine : official journal of the American College of Medical Genetics. 2011;13(9):777-84.

57. Gorwood P. Genetic association studies in behavioral neuroscience. In: Cruzio W, Gerlai R, editors. Handbook of molecular-genetic techniques for brain and behavior research. Amsterdam: Elsevier; 1999. p. 113-21.

58. Kim YJ, Jin HJ. Dissecting the genetic structure of Korean population using genome-wide SNP arrays. Gene \& Genomics. 2013;35(3):355-63.

\section{Submit your next manuscript to BioMed Central and we will help you at every step:}

- We accept pre-submission inquiries

- Our selector tool helps you to find the most relevant journal

- We provide round the clock customer support

- Convenient online submission

- Thorough peer review

- Inclusion in PubMed and all major indexing services

- Maximum visibility for your research

Submit your manuscript at www.biomedcentral.com/submit

C) Biomed Central 